\title{
Effect of Low-Dose Dexmedetomidine on the Anesthetic and Recovery Profile of Sevoflurane-Based Anesthesia in Patients Presenting for Supratentorial Neurosurgeries: A Randomized Double-Blind Placebo-Controlled Trial
}

\author{
Unnikrishnan Prathapadas ${ }^{1}$ \\ Manikandan Sethuraman ${ }^{1}$
}

\author{
Ajay Prasad Hrishi' ${ }^{1}$ Arulvelan Appavoo ${ }^{2}$ Smita Vimala'
}

\begin{abstract}
Address for correspondence Ajay Prasad Hrishi, DM, Division of Neuroanaesthesia, Department of Anaesthesiology, Sree Chitra Tirunal Institute for Medical Sciences and Technology, Thiruvananthapuram 695 011, Kerala, India

(e-mail: drajay@sctimst.ac.in).
\end{abstract}

J Neurosci Rural Pract 2020;11:267-273

\begin{abstract}
Background Dexmedetomidine could be a suitable adjuvant in neuroanesthesia due to its analgesic and anesthetic-sparing properties with the added advantage of facilitating intraoperative neuromonitoring. However, its recovery profile is still debated upon, as in neuroanesthesia, a prompt recovery is essential for postoperative neurologic assessment. We designed this study to evaluate the effect of dexmedetomidine on the anesthetic and recovery profile of patients presenting for supratentorial neurosurgeries. Materials and Methods Forty adult patients undergoing supratentorial surgeries were recruited in this prospective, randomized, double-blinded study and were divided into two groups: group S and group SD. Both groups received sevoflurane and fentanyl for maintenance, whereas group SD alone received a low dose of dexmedetomidine infusion. Recovery parameters, opioid consumption, Richmond AgitationSedation Scale (RASS) and visual analogue scale (VAS) scores, incidence of nausea and vomiting, and intraoperative hemodynamics were analyzed.

Results There were no statistically significant differences between the groups S and SD in case of recovery parameters-time taken (in minutes, presented as median with interquartile range [IQR]) for (1) eye-opening to command: $9.5(8-18)$ versus $22.5(5-47.5)(p=0.414)$; 2) following verbal command: 10.5 (8.25-29.5) versus 25 (10-28.75) ( $p=0.512)$; (3) extubation: 11 (9.25-22) versus $25(10-30)(p=0.277)$; and (4) getting oriented to place, time, and date: $23(20-52.75)$ versus $27.5(25-36.5)(p=0.121)$. Fentanyl consumption was significantly less in group SD $(451 \pm 39.3)$ versus group S $(524.3 \pm 144.1)(p=0.034)$. The median RASS score with IQR and the median VAS scores with IQR were comparable between the groups at all time points. Of the 20 patients in group S, 5 had complaints of nausea and vomiting compared with none in the group SD, although it was not statistically significant.

Keywords

- dexmedetomidine

- neuroanesthesia

- recovery

- supratentorial neurosurgery The hemodynamic parameters did not show a significant difference between the groups except for a surge in mean arterial pressure at 30 minutes in group $\mathrm{S}$.

Conclusion Low-dose dexmedetomidine as an adjuvant to sevoflurane- and fentanyl-based anesthesia could provide stable hemodynamics and lesser anesthetics and opioid consumption, without adversely affecting the recovery profile in patients undergoing supratentorial neurosurgical procedures.
\end{abstract}

DOI https://doi.org/ $10.1055 / \mathrm{s}-0040-1703968$ ISSN 0976-3147.
C2020 Association for Helping Neurosurgical Sick People
License terms

() (1) $\ominus \circledast$ 


\section{Introduction}

Anesthetic goal during the conduct of neurosurgery is to maintain a balance between optimal cerebral hemodynamics and oxygenation. An ideal anesthetic should provide a slack brain and excellent analgesia and facilitate a rapid recovery. Dexmedetomidine is a superselective $\alpha-2$ agonist that can reduce the consumption of anesthetics and provide optimum analgesia through its opioid-sparing property. ${ }^{1}$ It facilitates an ideal anesthetic background for neurosurgery as it does not interfere with intraoperative neuromonitoring and has an opioid-sparing effect, with the added advantage of preserving the respiratory drive in the immediate postoperative period. ${ }^{2}$ Neurosurgeries differ from routine general surgeries in terms of the longer duration and differing anesthesia concerns. ${ }^{2}$

The effect of dexmedetomidine in neurosurgeries has been evaluated in the past. However, these studies did not use the depth of anesthesia monitoring such as bispectral index scale (BIS) as an end point to titrate anesthetic drugs and therefore were inconclusive. ${ }^{3,4}$ Moreover, these studies had varying outcomes ranging from a delayed recovery to the recovery time remaining unaffected. ${ }^{1-4}$ The need for an early neurologic assessment in the postoperative period is of paramount importance in neuroanesthesia practice. Hence, a prompt recovery in the immediate postoperative period is one of the essential goals of neuroanesthesia practice. To address this lacuna in the scientific literature on dexmedetomidine, we decided to evaluate the effect of low-dose dexmedetomidine on the anesthetic and recovery profile of BIS-guided sevoflurane-based anesthesia in patients presenting for supratentorial neurosurgeries.

\section{Materials and Methods}

After obtaining approval from the Institutional Ethics Committee, the trial was registered in Clinical Trials RegistryIndia (CTRI/2019/01/017108). Forty consenting patients in the age group of 18 to 50 years, belonging to the ASA (American Society of Anesthesiologists) physical status I and II, undergoing elective supratentorial neurosurgeries were recruited in this prospective, randomized, double-blinded study. Patients allergic to dexmedetomidine, those with baseline heart rate $(\mathrm{HR})<50 \mathrm{bpm}$, those with a history of heart block, those on $\beta$-blockers, $\alpha$-methyldopa, or clonidine, those with coronary artery disease or left ventricular dysfunction, and pregnant or nursing women were excluded from the study. Also, patients with signs and symptoms of raised intracranial pressure (ICP) were excluded. Tab alprazolam $0.5 \mathrm{mg}$ was given on the previous night of the surgery as part of routine premedication.

Patients were randomized into two groups of 20 each. Group S patients received sevoflurane anesthesia for maintenance, and group SD patients received dexmedetomidine infusion along with sevoflurane anesthesia for maintenance. In group SD, we used dexmedetomidine diluted as $2 \mu \mathrm{g} / \mathrm{mL}$ at $0.2 \mu \mathrm{g} / \mathrm{kg} / \mathrm{h}$ as an adjuvant. This corresponded to an infusion of $0.1 \mathrm{~mL} / \mathrm{kg} / \mathrm{h}$ of the diluted drug. In group $\mathrm{S}$, we administered $0.1 \mathrm{~mL} / \mathrm{kg} / \mathrm{h}$ of normal saline.

\section{Randomization}

Patients were allocated randomly by envelope method using a random number table into two groups of 20 each by the principal investigator. Maintenance drugs, that is, dexmedetomidine/normal saline infusions, were prepared in identical syringes and were given to the attending anesthesiologist by the principal investigator. The assessment was performed by the attending anesthesiologist who was not an investigator of the study and was blinded to group allocation.

\section{Study Protocol}

In the operating room, the patient was connected to standard monitors, that is, electrocardiogram (ECG), pulse oximeter $\left(\mathrm{SpO}_{2}\right)$, and noninvasive blood pressure monitor. Additionally, the BIS Complete Monitoring System (Medtronic, Mansfield, Massachusetts, United States) also was used. BIS Quatro Sensor (Medtronic) was applied on the forehead as per the manufacturer's instruction on the nonoperating side. Baselines values were recorded from all the monitors before induction. Under local anesthesia using $2 \%$ lignocaine, peripheral venous access was established. Postinduction, end-tidal carbon dioxide $\left(\mathrm{EtCO}_{2}\right)$, train of four (TOF), and invasive arterial blood pressure were also monitored. All patients received intravenous (IV) fentanyl $2 \mu \mathrm{g} / \mathrm{kg}$ and were induced with the total calculated dose of IV propofol $2 \mathrm{mg} / \mathrm{kg}$ titrated to the loss of verbal response and a target BIS of 40 followed by IV vecuronium $0.1 \mathrm{mg} / \mathrm{kg}$ after confirming the adequacy of ventilation. Postintubation, all patients were ventilated in a volume control mode with 8 to $10 \mathrm{~mL} / \mathrm{kg}$ of tidal volume and respiratory rate set to achieve an end-tidal carbon dioxide pressure of 30 to $35 \mathrm{~mm} \mathrm{Hg}$. Anesthesia was maintained with $\mathrm{O}_{2}$, and air (50:50) mixture with sevoflurane titrated to a target BIS of 45 to 50 . As the stimulus varied during surgery, volatile agent concentrations were adjusted by $0.2 \%$ increments whenever the BIS values were out of the target range to ensure a BIS of 45 to 50 .

Postinduction, the study groups received the following drugs based on the group to which they were randomized:

- Group S: $0.1 \mathrm{~mL} / \mathrm{kg} / \mathrm{h}$ IV normal saline + sevoflurane titrated to BIS of 45 to 50 .

- Group SD: $0.2 \mu \mathrm{g} / \mathrm{kg} / \mathrm{h}$ dexmedetomidine + sevoflurane titrated to BIS of 45 to 50 .

In both groups, additional vecuronium boluses were used to keep the TOF below 2 throughout the surgical procedure. All patients received an infusion of fentanyl at $0.5 \mu \mathrm{g} / \mathrm{kg} / \mathrm{h}$ as a background analgesic agent till the end of the surgery. Apart from this constant maintenance dose, an additional bolus of fentanyl $1 \mu \mathrm{g} / \mathrm{kg}$ was administered before the application of skull clamps. Consistent elevation of $10 \%$ increase in HR and $10 \%$ increase in mean arterial pressure (MAP) without any confounding factors (such as neural reflex and iatrogenic changes in blood pressure for checking hemostasis) was considered as pain stimulus and was treated with a bolus of fentanyl $1 \mu \mathrm{g} / \mathrm{kg}$.

Toward the end of surgery during dural closure, all patients received IV paracetamol $15 \mathrm{mg} / \mathrm{kg}$ and IV ondansetron 
$0.1 \mathrm{mg} / \mathrm{kg}$. Maintenance drugs (dexmedetomidine/normal saline, fentanyl, and volatile agents) were stopped after the patient had been removed from surgical clamp. IV neostigmine $0.05 \mathrm{mg} / \mathrm{kg}$ and IV glycopyrrolate $4 \mu \mathrm{g} / \mathrm{kg}$ were given after the return of all the four twitches in TOF and a TOF ratio of $>0.7$. The patient was extubated once the patient started obeying commands and after ruling out any neurologic deficits. Rescue analgesia with $10 \mathrm{mg} / \mathrm{kg}$ of IV paracetamol was administered when the visual analogue scale (VAS) score was $\geq 3$ or on-demand postoperatively. IV ondansetron $4 \mathrm{mg}$ was administered immediately if the patient had nausea or vomiting.

\section{Data}

The following data were collected for each patient.

\section{Anesthesia Parameters}

The anesthesia parameters included the duration of anesthesia (intubation to extubation), the total dose of fentanyl administered, and end-tidal sevoflurane concentration (as \%) values after intubation to discontinuation of volatile agents (assessed every 10 minutes from the trend of the gas monitor and averaged). The hemodynamic variables such as HR and MAP were recorded every 10 minutes.

\section{Recovery Parameters}

The recovery parameters included the following:

1. Time between discontinuation of maintenance drugs to:

- Eye-opening to command

- Following verbal command (handgrip)

- Extubation

- Orientation to place, time, and date

2. Sedation and pain assessment (extubation, 30, 60, 90, and 120 minutes):

- Sedation assessment using the Richmond AgitationSedation Scale (RASS)

- Pain assessment using VAS

- Nausea and vomiting episodes

\section{Statistical Analysis}

Numerical data were expressed as mean \pm standard deviation if the distribution was normal or as median with an interquartile range (IQR) if not, and categorical data were expressed as frequencies. Association between categorical variables was tested using the chi-square test and Fisher's exact test. Continuous variables were compared using Student's $t$-test or the MannWhitney $U$-test. Recovery parameters were compared between the two groups using time comparison analysis of variance with posthoc analysis. A p-value of less than 0.05 was considered statistically significant. The data analysis was performed using SPSS version 16 (IBM SPSS Inc., Chicago, Illinois, United States).

\section{Results}

Forty patients were recruited in this study. There were no statistically significant differences between the groups in terms of age, height, body weight, and body mass index, as shown in - Table 1. There was no significant difference in the mean duration of surgery and anesthesia, as described in - Table $\mathbf{1}$. The time needed to achieve the primary recovery end points-(1) eye-opening, (2) verbal response, (3) extubation, and (4) orientation in time and place-for groups $S$ and $\mathrm{SD}$ is described in - Table 2. For eye-opening, the median time for group S was 9.5 minutes (IQR: 8-18 minutes), whereas for group SD, it was 22.5 minutes (IQR: 5-47.5 minutes). Though the time to eye- opening was longer in group SD, the difference was not statistically significant $(p=0.414)$. In case of verbal response, for group $\mathrm{S}$, the median time was 10.5 minutes (IQR: 8.25-29.5 minutes), whereas for group SD, it was 25 minutes (IQR: 10-28.75 minutes). This difference was not statistically significant $(p=0.512)$. The median extubation time for group $\mathrm{S}$ was 11 minutes (IQR: 9.5-22 minutes), whereas for group SD, it was 25 minutes (IQR: 10-30 minutes), as seen in - Table 2. There was no statistically significant difference between the two groups with regard to the time taken for extubation ( $p=0.277$ ). In terms of orientation postextubation, group $\mathrm{S}$ patients had taken a median time of 23 minutes (IQR: $20-52.75$ minutes) to get oriented in time and place, while group SD patients had

Table 1 Demographic parameters of patients in groups S and SD

\begin{tabular}{|c|c|c|c|c|c|}
\hline \multirow[t]{2}{*}{ Demographic parameters } & \multicolumn{2}{|c|}{ Group S $(N=20)$} & \multicolumn{2}{|c|}{ Group SD $(N=20)$} & \multirow[t]{2}{*}{$p$-Value } \\
\hline & Mean & Standard deviation & Mean & Standard deviation & \\
\hline Age (y) & 43.60 & 10.88 & 46.40 & 3.36 & 0.589 \\
\hline Height (cm) & 167.50 & 10.39 & 169.00 & 7.91 & 0.782 \\
\hline Weight (kg) & 67.00 & 9.39 & 64.80 & 5.54 & 0.640 \\
\hline BMI $\left(\mathrm{kg} / \mathrm{m}^{2}\right)$ & 23.82 & 1.92 & 22.70 & 1.61 & 0.284 \\
\hline $\begin{array}{l}\text { Mean duration of surgery } \\
\text { (min) }\end{array}$ & 355.9 & 62.7 & 347 & 72.19 & 0.67 \\
\hline $\begin{array}{l}\text { Mean duration of anesthesia } \\
\text { (min) }\end{array}$ & 372.9 & 56.8 & 380.2 & 62.4 & 0.62 \\
\hline
\end{tabular}

Abbreviations: BMI, body mass index; S, sevoflurane; SD, sevoflurane with dexmedetomidine. 
Table 2 Recovery parameters of patients in groups S and SD

\begin{tabular}{|l|l|l|l|l|l|}
\hline Recovery parameter & $\begin{array}{l}\text { Group S }(N=20), \\
\text { median time taken } \\
\text { to reach recovery } \\
\text { end point (minutes) }\end{array}$ & IQR & $\begin{array}{l}\text { Group SD }(N=20) \text {, median time } \\
\text { taken to reach recovery end } \\
\text { point (minutes) }\end{array}$ & IQR & $p$-Value \\
\hline Eye-opening & 9.5 & $8-18$ & 22.5 & $5-47.5$ & 0.414 \\
\hline Verbal response & 10.5 & 8.2529 .5 & 25 & $10-28.75$ & 0.512 \\
\hline Extubation & 11 & $9.25-22$ & 25 & $10-30$ & 0.277 \\
\hline $\begin{array}{l}\text { Orientation in time and } \\
\text { place }\end{array}$ & 23 & $20-52.75$ & 27.5 & $25-36.5$ & 0.121 \\
\hline
\end{tabular}

Abbreviations: IQR, interquartile range; S, sevoflurane; SD, sevoflurane with dexmedetomidine.

taken a median time of 27.5 (IQR: 25-36.5 minutes), which was not statistically significant $(p=0.121)$ (-Table 2 ).

The total fentanyl consumption and end-tidal sevoflurane requirement to maintain a BIS of 45 to 50 in both the groups is shown in - Table 3 . The consumption of fentanyl in group SD was found to be significantly lower than that in group $\mathrm{S}(p=0.034)$. Though the end-tidal sevoflurane was lower in group SD, it was not statistically significant as compared with the $S$ group $(p=0.065)$. The median RASS scores with $\mathrm{IQR}$ at various time points in both the groups were analyzed $(-$ Fig. 1). There were no statistically significant differences between the median RASS scores with IQR between the groups at any time point. The median VAS scores with IQR at various time points were evaluated, and the results are depicted in - Fig. 2. The median VAS scores with IQR were comparable between the groups at all time points. Out of 20 patients, 5 had nausea and vomiting in group S compared with none in group SD, which was not statistically significant. Group S had a higher MAP compared with group SD, as shown in - Fig. $\mathbf{3}$, but it was not statistically significant except at 30 minutes postinduction $(p=0.042)$. Though not statistically significant, the HR was lower in group SD at all time points as compared with group $\mathrm{S}$.

\section{Discussion}

Supratentorial neurosurgeries require an anesthetic regimen, which ensures optimal cerebral perfusion, stable hemodynamics, preserved autoregulation, excellent analgesia, and rapid recovery. ${ }^{2,3}$ The ideal regimen should also facilitate intraoperative neuromonitoring, which has now become an integral part of neuroanesthesia practice. ${ }^{5}$ Multiple drugs such as opioids, benzodiazepine, and dexmedetomidine can be used as adjuvants for facilitating these goals. Opioids in this scenario could affect the recovery, delay the neurologic assessment, and lead to a high incidence of postoperative nausea and vomiting (PONV), ${ }^{2}$ whereas dexmedetomidine as an adjuvant achieves most of these targets without having any deleterious effects on the cerebral perfusion pressure, ICP, and cerebral oxygen demand $\left(\mathrm{CMRO}_{2}\right)^{6-9}$ Dexmedetomidine as an adjuvant will facilitate intraoperative neuromonitoring as it does not affect the recording of motor evoked potential, somatosensory evoked potentials, and electrocorticography. ${ }^{2,10}$ Additionally, it has analgesic and opioid-sparing properties along with antiemetic properties, making it the right choice for neuroanesthesia practice. ${ }^{2}$ The main concern that limited the use of dexmedetomidine was the doubtful recovery profile when administered along with volatile agents. ${ }^{1,11}$ Moreover, the recovery profile of neurosurgeries is different as the long duration can result in a cumulative drug effect, thereby delaying the recovery and thus hampering the prompt neurologic assessment in the

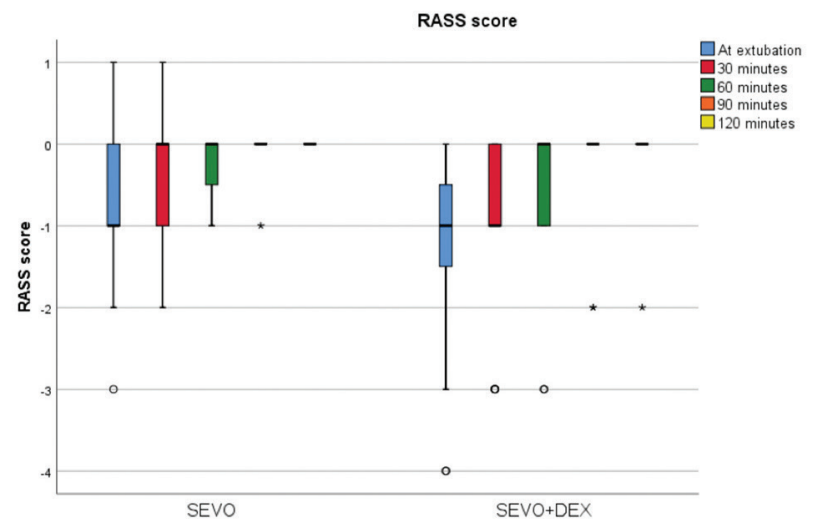

Fig. 1 Comparison of the median RASS score with interquartile range at various time points of both SEVO and SEVO + DEX groups. RASS, Richmond Agitation-Sedation Scale; SEVO, sevoflurane; SEVO + DEX, sevoflurane with dexmedetomidine.

Table 3 Comparison of fentanyl consumption and end-tidal sevoflurane in both the group of patients

\begin{tabular}{|c|c|c|c|c|c|c|c|}
\hline \multirow[t]{2}{*}{ Group } & \multirow[t]{2}{*}{$N$} & \multicolumn{2}{|c|}{ Fentanyl (mg) } & $p$-Value & \multicolumn{2}{|c|}{ End-tidal sevoflurane (\%) } & \multirow{4}{*}{$\begin{array}{l}p \text {-Value } \\
0.065\end{array}$} \\
\hline & & Mean & Standard deviation & \multirow[t]{3}{*}{0.034} & Mean & Standard deviation & \\
\hline$S$ & 20 & 524.3 & 144.1 & & 1.89 & 0.4 & \\
\hline SD & 20 & 451.0 & 39.3 & & 1.68 & 0.3 & \\
\hline
\end{tabular}

Abbreviations: S, sevoflurane; SD, sevoflurane with dexmedetomidine.

aEnd-tidal sevoflurane (\%) required to maintain bispectral index between 45 and 50 . 
immediate postoperative period. As there were limited data on the recovery characteristics of neurosurgical patients who received dexmedetomidine as an adjuvant, we designed this study to find the effect of dexmedetomidine on time taken for recovery and to assess the quality of recovery in patients undergoing supratentorial surgeries.

In our study, though there was a noticeable delay in the recovery parameters for the patients in the dexmedetomidine group, it was statistically not significant. We also found that the median RASS scores with IQR were comparable between

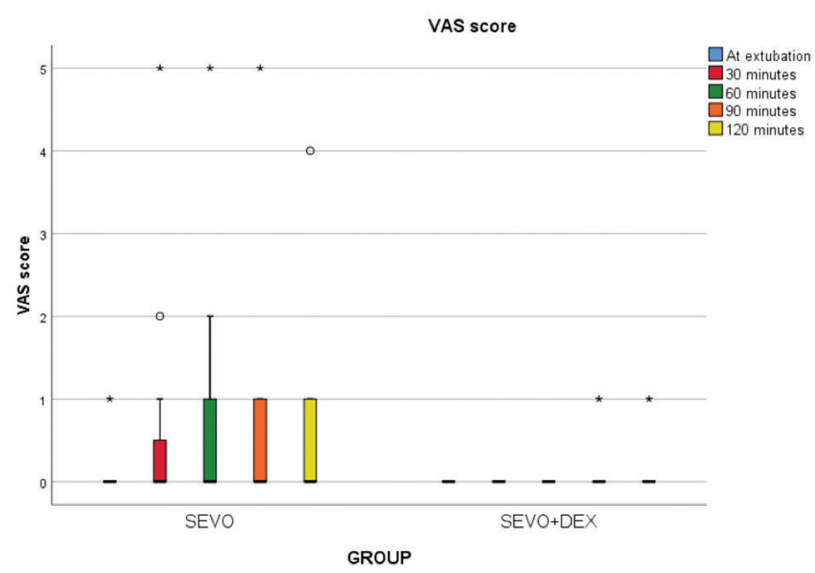

Fig. 2 Comparison of the median VAS score with interquartile range at various time points of both SEVO and SEVO + DEX groups. SEVO, sevoflurane; SEVO + DEX, sevoflurane with dexmedetomidine; VAS, visual analogue scale. both of the groups. Dexmedetomidine decreases the requirements of volatile agents in a dose-dependent manner. It also reduces the opioid requirement significantly in the perioperative period. ${ }^{1,12-16}$ These factors must have helped in avoiding a significant delay in recovery of patients in the dexmedetomidine group. In our study, the requirement of fentanyl boluses was significantly lower in the dexmedetomidine group. Though not statistically significant, the end-tidal concentration of sevoflurane required to maintain a BIS of 45 to 50 was found to be lower in the dexmedetomidine group. This reduction in the requirement of anesthetics and opioids could have contributed to the favorable effect on the recovery. Apart from this, the avoidance of a loading dose and the use of BIS-guided titration of the depth of anesthesia might have further aided the optimal dosing of the anesthetics, leading to a normal recovery. ${ }^{17,18}$

Chakrabarti et al evaluated the effects of dexmedetomidine as an adjuvant to propofol-based anesthesia in posterior fossa surgery. ${ }^{19}$ They concluded that dexmedetomidine reduced propofol requirements in posterior fossa neurosurgeries, with comparable recovery profile to the group without dexmedetomidine. Therefore, this finding that the recovery is not getting affected, even in procedures involving the posterior fossa where the target area of action of dexmedetomidine, the locus ceruleus, is situated, reflects on the favorable safety profile of the drug in neurosurgical anesthesia practice. Ilhan et al studied the effects of dexmedetomidine as an adjuvant to isoflurane in one group and compared it with a group that received a combination of fentanyl and isoflurane in patients undergoing supratentorial surgeries. ${ }^{16}$

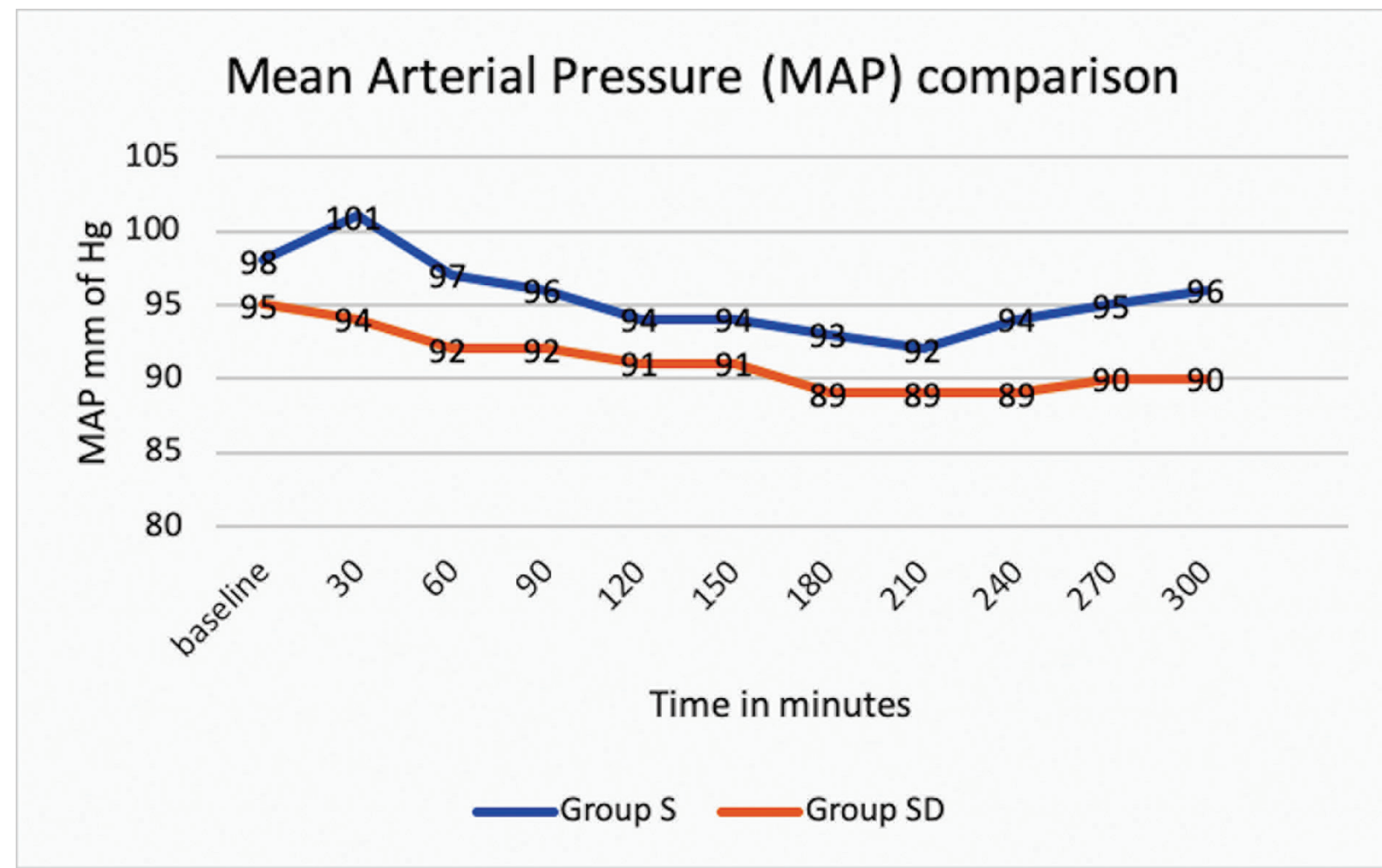

Fig. 3 Comparison of the mean arterial pressure at various time points of both the sevoflurane group and the sevoflurane with dexmedetomidine group. 
They found that the dexmedetomidine group had shorter recovery time compared with the fentanyl group. They had administered additional boluses of fentanyl in the dexmedetomidine group for painful stimulus, which was not quantified, and the anesthesia was not titrated with the help of BIS or any other depth of anesthesia monitors. In neuroanesthesia practice, dexmedetomidine cannot totally replace fentanyl as an adjuvant as it has an inferior analgesic profile and neurosurgical population encounter higher pain stimulus. Dexmedetomidine plays a vital role as an adjuvant by reducing the perioperative opioid requirement. ${ }^{14,15,20}$ To overcome the aforementioned issue, both the groups in our study received fentanyl-based anesthesia, and we evaluated the effects of dexmedetomidine as an adjuvant to one of the two groups while the anesthesia was titrated to a BIS of 45 to 50 .

In our study, the dexmedetomidine group had a better hemodynamic profile. This concurred with the findings of the previous studies, which showed that intraoperative dexmedetomidine offers excellent hemodynamic stability at all phases of neurosurgeries. ${ }^{3,20}$ We observed that the MAP was significantly lower in the dexmedetomidine group immediately after the application of the Mayfield clamp, indicating effective suppression of the sympathetic surge associated with the painful stimulus. Our study did not show any significant reduction of HR requiring intervention in the dexmedetomidine group. Tan and Ho had found that the incidence of bradycardia that requires intervention is higher with the administration of a loading dose and higher infusion rate. ${ }^{21}$ In our study, we had omitted the loading dose of dexmedetomidine and used a low dose for maintenance, which could have resulted in stable hemodynamics while preserving dexmedetomidine's desirable properties. Use of intraoperative BIS might have further optimized the anesthetic management, thus reducing the incidence of adverse hemodynamic events in the study group.

Optimal analgesia is of paramount importance in the neurosurgical population as poorly controlled pain results in raised ICP and unstable hemodynamics, both of which could affect the patient's recovery and outcome. ${ }^{22}$ Adequate analgesia also reduces the incidence of postoperative nausea, vomiting, and respiratory complications. The pharmacological armamentarium for perioperative analgesia includes nonsteroidal anti-inflammatory drugs (NSAIDs), opioids, and paracetamol. ${ }^{23}$ NSAIDs are not recommended in neurosurgical procedures due to their potential to cause platelet dysfunction and due to an increased risk of causing bleeding inside a closed space. ${ }^{24}$ Though opioids are routinely used agents in neurosurgeries, higher doses can depress the sensorium, resulting in delayed neurologic assessment along with respiratory depression and PONV. Respiratory depression could also lead to $\mathrm{CO}_{2}$ retention, which, in turn, leads to a rise in ICP, thereby worsening the postoperative recovery. Dexmedetomidine as an adjuvant offers a good analgesic profile, reduces the requirement of opioids, and does not affect the respiratory drive. ${ }^{1,20,25}$

The incidence of nausea and vomiting in neurosurgical patients has been reported as 55 to $70 \% .26-28$ It increases the ICP as well as the risk of hematoma formation. Also, the neurosurgical patients are at a high risk of aspiration due to their altered sensorium and weakened protective airway reflexes. ${ }^{29}$ In our study also, the dexmedetomidine group had a lower incidence of nausea and vomiting, which was not statistically significant. The meta-analysis by Peng et al revealed that the administration of dexmedetomidine intraoperatively reduced the antiemetic requirements in the postoperative period, possibly by reducing hemodynamic fluctuations and due to the opioid-sparing action. ${ }^{20}$ Gopalakrishna et al used the highest recommended maintenance dose of $0.7 \mu \mathrm{g} / \mathrm{kg} / \mathrm{h}$ in patients undergoing pituitary surgeries and had got a more explicit benefit in reducing PONV (22.7\% in the dexmedetomidine group vs $40.9 \%$ in the control group). ${ }^{2}$ The lower maintenance dosage of dexmedetomidine in our study could have reduced its antiemetic potential in our study. ${ }^{2}$

\section{Limitation}

Use of an analgesia nociception index monitor might have further quantified the analgesic potential of dexmedetomidine along with fentanyl.

\section{Conclusion}

Our study demonstrated that low-dose dexmedetomidine as an adjuvant to sevoflurane- and fentanyl-based anesthesia can provide stable hemodynamics and lesser anesthetic and opioid consumption, without adversely affecting the recovery profile in patients undergoing supratentorial neurosurgical procedures. Avoiding the loading dose and lowdose maintenance is the key to prevent the adverse effects of dexmedetomidine when used as an adjuvant to sevoflurane anesthesia.

\section{Authors' Contributions}

The article has been read and approved by all the authors, the requirements for authorship have been met, and each author believes that the article represents honest work.

\section{Conflict of Interest}

None declared.

\section{References}

1 Khan ZP, Munday IT, Jones RM, Thornton C, Mant TG, Amin D. Effects of dexmedetomidine on isoflurane requirements in healthy volunteers. 1: pharmacodynamic and pharmacokinetic interactions. Br J Anaesth 1999;83(3):372-380

2 Gopalakrishna KN, Dash PK, Chatterjee N, Easwer HV, Ganesamoorthi A. Dexmedetomidine as an anesthetic adjuvant in patients undergoing transsphenoidal resection of pituitary tumor. J Neurosurg Anesthesiol 2015;27(3):209-215

3 Bekker A, Sturaitis M, Bloom M, et al. The effect of dexmedetomidine on perioperative hemodynamics in patients undergoing craniotomy. Anesth Analg 2008;107(4):1340-1347

4 Lee J. Insight into the effects of dexmedetomidine on intraoperative hemodynamics and postanesthetic recovery speed. Korean J Anesthesiol 2012;62(2):111-112

5 Bhagat H, Dash HH. Anaesthesiologist's role in the management of an epileptic patient. Indian J Anaesth 2006;50(1):20-26 
6 Khallaf M, Thabet AM, Ali M, Sharkawy E, Abdel-rehim S. The effect of dexmedetomidine versus propofol in traumatic brain injury: evaluation of some hemodynamic and intracranial pressure changes. Egypt J Neurosurg 2019;34(1):17

7 Farag E, Argalious M, Sessler DI, Kurz A, Ebrahim ZY, Schubert A. Use of $\alpha(2)$-agonists in neuroanesthesia: an overview. Ochsner J 2011;11(1):57-69

8 Aryan HE, Box KW, Ibrahim D, Desiraju U, Ames CP. Safety and efficacy of dexmedetomidine in neurosurgical patients. Brain Inj 2006;20(8):791-798

9 Rozet I. Anesthesia for functional neurosurgery: the role of dexmedetomidine. Curr Opin Anaesthesiol 2008;21(5):537-543

10 Thornton C, Lucas MA, Newton DE, Doré CJ, Jones RM. Effects of dexmedetomidine on isoflurane requirements in healthy volunteers. 2: auditory and somatosensory evoked responses. Br J Anaesth 1999;83(3):381-386

11 Patel CR, Engineer SR, Shah BJ, Madhu S. Effect of intravenous infusion of dexmedetomidine on perioperative haemodynamic changes and postoperative recovery: a study with entropy analysis. Indian J Anaesth 2012;56(6):542-546

12 Aantaa R, Jaakola ML, Kallio A, Kanto J. Reduction of the minimum alveolar concentration of isoflurane by dexmedetomidine. Anesthesiology 1997;86(5):1055-1060

13 Aho M, Erkola O, Kallio A, Scheinin H, Korttila K. Dexmedetomidine infusion for maintenance of anesthesia in patients undergoing abdominal hysterectomy. Anesth Analg 1992;75(6):940-946

14 Arain SR, Ruehlow RM, Uhrich TD, Ebert TJ. The efficacy of dexmedetomidine versus morphine for postoperative analgesia after major inpatient surgery. Anesth Analg 2004;98(1):153-158

15 Hall JE, Uhrich TD, Barney JA, Arain SR, Ebert TJ. Sedative, amnestic, and analgesic properties of small-dose dexmedetomidine infusions. Anesth Analg 2000;90(3):699-705

16 Ilhan O, Koruk S, Serin G, Erkutlu I, Oner U. Dexmedetomidine in the supratentorial craniotomy. Eurasian J Med 2010;42(2):61-65

17 Recart A, Gasanova I, White PF, et al. The effect of cerebral monitoring on recovery after general anesthesia: a comparison of the auditory evoked potential and bispectral index devices with standard clinical practice. Anesth Analg 2003;97(6):1667-1674

18 Wong J, Song D, Blanshard H, Grady D, Chung F. Titration of isoflurane using BIS index improves early recovery of elderly patients undergoing orthopedic surgeries. Can J Anaesth 2002;49(1):13-18

19 Chakrabarti D, Kamath S, Madhusudan Reddy KR, Srinivas DB, Manohar N, Masapu D. Effect of adjunctive dexmedetomidine on anesthesia and analgesia requirement and recovery characteristics during Bispectral Index-guided anesthesia for cerebello-pontine angle surgeries: a randomized clinical trial. J Anaesthesiol Clin Pharmacol 2018;34(4):496-502

20 Peng K, Wu S, Liu H, Ji F. Dexmedetomidine as an anesthetic adjuvant for intracranial procedures: meta-analysis of randomized controlled trials. J Clin Neurosci 2014;21(11):1951-1958

21 Tan JA, Ho KM. Use of dexmedetomidine as a sedative and analgesic agent in critically ill adult patients: a meta-analysis. Intensive Care Med 2010;36(6):926-939

22 Dahl JB, Kehlet H. Preventive analgesia. Curr Opin Anaesthesiol 2011;24(3):331-338

23 Vadivelu N, Kai AM, Tran D, Kodumudi G, Legler A, Ayrian E. Options for perioperative pain management in neurosurgery. J Pain Res 2016;9:37-47

24 Palmer JD, Sparrow OC, Iannotti F. Postoperative hematoma: a 5-year survey and identification of avoidable risk factors. Neurosurgery 1994;35(6):1061-1064

25 Maze M, Scarfini C, Cavaliere F. New agents for sedation in the intensive care unit. Crit Care Clin 2001;17(4):881-897

26 Leslie K, Troedel S, Irwin K, et al. Quality of recovery from anesthesia in neurosurgical patients. Anesthesiology 2003;99(5):1158-1165

27 Fabling JM, Gan TJ, El-Moalem HE, Warner DS, Borel CO. A randomized, double-blinded comparison of ondansetron, droperidol, and placebo for prevention of postoperative nausea and vomiting after supratentorial craniotomy. Anesth Analg 2000;91(2):358-361

28 Meng L, Quinlan JJ. Assessing risk factors for postoperative nausea and vomiting: a retrospective study in patients undergoing retromastoid craniectomy with microvascular decompression of cranial nerves. J Neurosurg Anesthesiol 2006;18(4):235-239

29 Fabling JM, Gan TJ, Guy J. Borel CO, el-Moalem HE, Warner DS. Postoperative nausea and vomiting. A retrospective analysis in patients undergoing elective craniotomy. J Neurosurg Anesthesiol 1997;9(4):308-312 